\title{
Esophageal Disorders Not Yet Addressed by High-resolution Manometry
}

TO THE EDITOR: We greatly appreciate the insight provided by Wang et $\mathrm{al}^{1}$ regarding their recent review of the esophageal disorders not assessed by the Chicago classification of motility disorders of the esophagus. This is an important issue as many people still fail to understand that the Chicago classification was designed to describe and categorize distal esophageal motor disorders focused on dysphagia and was not meant to be a global classification across the entire spectrum of esophageal disorders. All patients undergoing manometry will have a Chicago classification diagnosis, however, there may be other motor abnormalities of the upper esophageal sphincter, proximal esophagus or esophagogastric junction and proximal stomach that may be important in the patients presenting complaints and these need to be described separately from the Chicago classification diagnosis.

To utilize the Chicago classification, one has to follow specific rules and calculate specific metrics in a predefined order and the analysis is confined to an assessment during 10 supine $5 \mathrm{~mL}$ water swallows. ${ }^{2}$ We experienced that changing position elicited a change in diagnosis in about $10 \%$ of studies, and that provocative bolus challenges modified the diagnoses by increasing the number of patients classified with an esophagogastric junction outflow obstruction. ${ }^{3}$ However, this did require utilization of different standard values and thresholds to allow for a refined characterization and represents one aspect where the Chicago classification diagnosis can be complemented. Similarly, the Chicago classification is also restricted to assessing patients before definitive treatment and although the Chicago classification can be modified to assess patients after antireflux procedures, bariatric surgery or treatments focused on disrupting the lower esophageal sphincter in achalasia; there are no reference ranges to define what is normal in the post-operative state. Nevertheless, the Chicago classification metrics, such as the integrated relaxation pressure and intrabolus pressure pattern, can help one discern whether there is an outflow obstruction after intervention and continued abnormal peristalsis. ${ }^{4,5}$ Thus, it is likely that the met- rics described in the Chicago classification can be utilized, or modified, to help define disorders outside of those that are focused on distal esophageal motor function.

Moving forward, the next steps in the evolution of high resolution manometry and esophageal pressure topography should focus on describing specific disease related processes highlighted in the review published by Wang et al, ${ }^{1}$ such as disorders related to gastroesophageal reflux, upper esophageal sphincter and proximal esophageal dysfunction in dysphagia, post-prandial complaints of regurgitation/possible rumination syndrome and postoperative assessment of symptomatic patients. This will require rigorous evaluation with careful description of normal thresholds and will require outcome data. This is no easy task as the evolution of the Chicago classification to its final version took almost 5 years and it is still being refined.

Initial steps in the process of categorizing esophageal motor dysfunction as it relates to gastroesophageal reflux, are currently underway. Hoshino et $\mathrm{al}^{6}$ have described new metrics of defining esophagogastric junction function as an antireflux barrier using modifications of the Chicago classification metrics and correlates of ineffective motility have been defined for esophageal pressure topography. ${ }^{7}$ Additionally, more emphasis on post-prandial assessments and provocative meals are also being studied to help elucidate mechanism of reflux that may be contributing to the patients underlying symptoms and there are new definitions for the assessment of transient lower esophageal sphincter relaxation using high resolution manometry. ${ }^{8,9}$ These are promising advances, however, we are only in the preliminary stages and although many have described motor abnormalities in the upper sphincter and post-prandial state, there is a paucity of reference data and consensus regarding terminology and definitions to help define new classifications for these disorders.

Thus, the Chicago classification should be utilized as it was intended and designed with the idea that it can be complemented by an assessment of motor function that extends beyond the distal 
esophagus and 10 supine water swallows. We look forward to future work that may lead to a parallel classification scheme for other disorders not covered by the Chicago classification and we look forward to another great city taking over where Chicago left off.

\section{Frédéric Nicodème and John E Pandolfino}

Division of Gastroenterology, Department of Medicine, Northwestern University Feinberg School of Medicine, Chicago, Illinois, USA

1. Wang YT, Yazaki E, Sifrim D. High-resolution manometry: esophageal disorders not addressed by the "Chicago classification". J Neurogastroenterol Motil 2012;18:365-372.

2. Bredenoord AJ, Fox M, Kahrilas PJ, et al. Chicago classification criteria of esophageal motility disorders defined in high resolution esophageal pressure topography. Neurogastroenterol Motil 2012; 24(suppl 1):57-65.

3. Xiao Y, Read A, Nicodeme F, Roman S, Kahrilas PJ, Pandolfino JE. The effect of a sitting vs supine posture on normative esophageal pressure topography metrics and Chicago classification diagnosis of esophageal motility disorders. Neurogastroenterol Motil 2012;24: e509-e 516

4. Nicodème F, de Ruigh A, Xiao Y, et al. A Comparison of symptom severity and bolus retention to Chicago classification esophageal pressure topography metrics in patients with achalasia. Clin Gastroenterol Hepatol Published Online First: 16 Oct 2012. doi: 10.1016/j.cgh.2012.10.015

5. Roman S, Kahrilas PJ, Mion F, et al. Partial recovery of peristalsis after myotomy for achalasia; more the rule than the exception. Arch Surg 2012 (In press)

6. Hoshino M, Sundaram A, Mittal SK. Role of the lower esophageal sphincter on acid exposure revisited with high-resolution manometry. J Am Coll Surg 2011;213:743-750.

7. Xiao Y, Kahrilas PJ, Kwasny MJ, et al. High-resolution manometry correlates of ineffective esophageal motility. Am J Gastroenterol 2012; 107:1647-1654.

8. Sweis R, Anggiansah A, Wong T, Kaufman E, Obrecht S, Fox M. Normative values and inter-observer agreement for liquid and solid bolus swallows in upright and supine positions as assessed by esophageal high-resolution manometry. Neurogastroenterol Motil 2011; 23:509. e198.

9. Roman S, Zerbib F, Belhocine K, des Varannes SB, Mion F. High resolution manometry to detect transient lower oesophageal sphincter relaxations: diagnostic accuracy compared with perfused-sleeve manometry, and the definition of new detection criteria. Aliment Pharmacol Ther 2011;34:384-393.

\section{Conflicts of interest: None.}

